\title{
UCRL-TR-521592-REV-1
}

\section{Godiva IV and Juliet Diagnostics CED-1, Rev. 1 (IER-176)}

J. C. Scorby

Lawrence Livermore National Laboratory

W. L. Myers

Los Alamos National Laboratory

March 28, 2012 


\section{Auspices}

This work performed under the auspices of the U.S. Department of Energy by Lawrence Livermore National Laboratory under Contract DE-AC52-07NA27344.

\section{Disclaimer}

This document was prepared as an account of work sponsored by an agency of the United States government. Neither the United States government nor Lawrence Livermore National Security, LLC, nor any of their employees makes any warranty, expressed or implied, or assumes any legal liability or responsibility for the accuracy, completeness, or usefulness of any information, apparatus, product, or process disclosed, or represents that its use would not infringe privately owned rights. Reference herein to any specific commercial product, process, or service by trade name, trademark, manufacturer, or otherwise does not necessarily constitute or imply its endorsement, recommendation, or favoring by the United States government or Lawrence Livermore National Security, LLC. The views and opinions of authors expressed herein do not necessarily state or reflect those of the United States government or Lawrence Livermore National Security, LLC, and shall not be used for advertising or product endorsement purposes.

\section{Executive Summary}

The Juliet experiment is currently in preliminary design (IER-128). This experiment will utilize a suite of diagnostics to measure the physical state of the device (temperature, surface motion, stress, etc.) and the total and time rate of change of neutron and gamma fluxes. A variety of potential diagnostics has been proposed in this CED-1 report. Based on schedule and funding, a subset of diagnostics will be selected for testing using the Godiva IV pulsed reactor as a source of neutrons and gammas. The diagnostics development and testing will occur over a two year period (FY12-13) culminating in a final set of diagnostics to be fielded for he Juliet experiment currently proposed for execution in FY15. 


\section{Introduction}

A suite of diagnostics are being proposed for use in the Juliet experiment (IER-128). In order to calibrate and test the diagnostics prior to use, the LLNL calibration facility, NSTec Dense Plasma Focus, and NCERC Godiva IV pulsed reactor will be used to provide intense sources of neutrons and gammas. Due to the similarities of the Godiva IV and Juliet radiation fields, the diagnostics being developed and tested for Juliet can also play an on-going role in diagnostics for Godiva IV as well as, perhaps, other critical assembly experiments.

Similar work is also being conducted for IER-147 for the purpose of characterizing the Godiva IV radiation field in support of an upcoming international nuclear accident dosimetry exercise; and LANL will be fielding an extensive set of activation foils to determine the energy spectrum utilizing threshold reactions for an HEU assembly under IER-153. These measurements can provide valuable data and methodology relevant to the calibration of Juliet diagnostics.

\section{Collaborations}

LANL and LLNL have strong diagnostics groups supporting NIF, nuclear nonproliferation, UGTs, subcrits, etc. Expertise from these groups has been sought in the selection of diagnostics and some collaborations have been established. The LLNL Test Readiness Program has offered to field and analyze data from the Alpha Box scintillator/PD/PMT system, neutron trap, CVD Diamond, and Vacuum Compton Diodes (see table below). The LLNL Radiochemistry and Radiation Safety Groups will field and measure activation and radiochemistry foils and LANL will field foils based on the results of those being fielded for IER-153. The LLNL Advanced Detector Design Group is designing and calibrating a neutron time of flight spectrometer. These collaborations support the Juliet experiment and also help regenerate or maintain diagnostic capabilities at LLNL needed for other programs.

\section{Diagnostics Development and Testing Plan}

The diagnostics schedule spans FY12 and FY13. Testing of diagnostics will fall under two campaigns. Primary diagnostics are those considered to provide the highest probability of success and are ready or near ready-to-deploy commercial or LLNL assets. The development and testing of these diagnostics will occur in FY12 and early FY13, contingent on the Godiva IV start-up schedule, with results reported in mid FY13. Additional diagnostics, designated as secondary, will be tested during FY13. The complete schedule of milestones and deliverables is included in the NCSP 5-yr. Plan.

Some diagnostics cannot be tested as they will be used prior to actual deployment for Juliet. These include diagnostics internal to the assembly: micro-fission meters, thermocouples and RTDs. However, testing external to Godiva IV and/or within the 
glory hole, as well as past usage of thermocouples and RTDs, can establish their viability for expected Juliet radiation and temperature fields.

An initial set of measurements will be made to characterize the room environment. These measurements support both IER-147 and this IER-176. The measurements will allow a determination of the neutron energy spectrum of the room return neutrons using a "clean" ${ }^{252} \mathrm{Cf}$ source as the initiating source of neutrons. This data is necessary to properly calibrate foils and detector responses expected to be used during Godiva IV and Juliet operations. Refer to the CED-1 report for IER-147 for a listing of all detectors being considered and the details of their sensitivities and expected accuracies. The most promising and readily available of them are included in the table of diagnostics presented later in this report.

Pending approval of CED-1, LLNL will proceed to final design CED-2. The following actions will need to be taken for CED-2:

- Preparation of all documents needed for procurements, instrument loan agreements, and agreements for collaborative work

- Development of a comprehensive LLNL test plan

- Identification of applicable NSTec and Laboratory requirements for performing work with diagnostic equipment within the NCERC

- Qualification of LLNL personnel and collaborators

- Identification of all necessary elements of NSTec "work packages" to enable introduction of LLNL equipment to the DAF, installation within NCERC, utilization by LLNL personnel and collaborators, handling of radioactive materials, return of equipment to LLNL

- Identification of any necessary changes to Laboratory Secondary Real Estate Operating Permits

- Identification and starting work on resolving any authorization basis issues

Upon approval of final design, LLNL will complete the items described above during the initial experiment execution initiation phase (CED-3a), and deploy all necessary equipment to the NNSS.

\section{Project Risks and Risk Management}

Budget limitations at other laboratories may preclude their ability to participate in the actual experiments within NCERC. Instrument loans may not be possible from other laboratories or LLNL organizations due to schedule conflicts requiring their use at the home organization during the time experiments are scheduled at NCERC. Schedule delays may occur during Godiva IV-IV reassembly complicating schedule planning.

Budget limitations for this task preclude full transfer of measurement responsibilities to collaborating organizations unless there is cost sharing. If other organizations were unable to share the cost burden, a smaller suite of diagnostics would need to be deployed. Use of existing ready-to-deploy assets from other organizations, with minimal start-up 
requirements, best avoids these risks. LLNL is negotiating cost sharing to provide the best collaborative framework possible based on funding.

\section{Diagnostics Suite}

The following table includes all the diagnostics under consideration for Juliet. Not all the diagnostics in the table will end up being tested or fielded due to budget and schedule constraints and the expected success of primary or secondary diagnostics. Those which are considered as primary diagnostics and intended to be tested in FY12 and early FY13 are marked with a "P" in the table. Secondary diagnostics are marked with an "S" for potential testing later in FY13.

\begin{tabular}{|c|c|c|}
\hline \multicolumn{3}{|c|}{ Diagnostics } \\
\hline $\begin{array}{c}\text { Type and } \\
\text { Designation }\end{array}$ & Description & Measured Quantity \\
\hline \multicolumn{3}{|c|}{ Internal to Assembly } \\
\hline $\begin{array}{l}\text { MICRO-FMS } \\
\quad \mathbf{P}\end{array}$ & $\begin{array}{l}\text { Micro-fission chambers } \\
\text { inserted in core at } 0.2,0.5 \text {, and } \\
0.8 \mathrm{~L} \text {. }\end{array}$ & $\begin{array}{l}\text { Current rate vs. time corresponding to local } \\
\text { neutron flux at detector location. }\end{array}$ \\
\hline FIBER OPTIC & $\begin{array}{l}\text { Fiber optic cables with pre- } \\
\text { drilled holes inserted in core at } \\
0.2 \text { and } 0.8 \mathrm{~L} \text { in a spiral radial } \\
\text { configuration. }\end{array}$ & $\begin{array}{l}\text { Light pulses corresponding to shock arrival } \\
\text { times at each hole. }\end{array}$ \\
\hline FIBER OPTIC & $\begin{array}{l}\text { Fiber optic cable wound } \\
\text { radially around core in gap at } \\
0.8 \mathrm{~L}\end{array}$ & $\begin{array}{l}\text { Changes in interference pattern as a function } \\
\text { of time corresponding to surface outward } \\
\text { velocity as a function of time. }\end{array}$ \\
\hline $\begin{array}{l}\text { ACTIVATION } \\
\text { AND RADCHEM } \\
\text { FOILS }\end{array}$ & $\begin{array}{l}\text { Activation foils located at } \\
\text { internal points. Various foil } \\
\text { materials, no shielding. }\end{array}$ & $\begin{array}{l}\text { Neutron induced radioactivity corresponding } \\
\text { to integrated neutron flux at foil location. }\end{array}$ \\
\hline $\begin{array}{l}\text { THERMOCOUPLES } \\
\text { RTDS }\end{array}$ & $\begin{array}{l}\text { "Intrinsic" thermocouples and } \\
\text { RTDs located at several internal } \\
\text { points. }\end{array}$ & $\begin{array}{l}\text { Current rate vs. time corresponding to } \\
\text { temperature at the thermocouple/RTD } \\
\text { location. }\end{array}$ \\
\hline LIF & $\begin{array}{l}\text { Laser induced fluorescence of } \\
\text { flour added to surface, pinhole } \\
\text { FO into assembly }\end{array}$ & $\begin{array}{l}\text { Change in decay rate of induced fluorescence } \\
\text { corresponding to surface temperature. }\end{array}$ \\
\hline
\end{tabular}




\begin{tabular}{|c|c|c|}
\hline $\begin{array}{l}\text { Type and } \\
\text { Designation }\end{array}$ & Description & Measured Quantity \\
\hline \multicolumn{3}{|c|}{ External to Assembly } \\
\hline $\begin{array}{l}\text { COMPTON } \\
\text { DIODES } \\
\mathbf{S}\end{array}$ & $\begin{array}{l}\text { Compton diode, collimated } \\
\text { view, multiple gains. }\end{array}$ & $\begin{array}{l}\text { Current rate vs. time corresponding to }{ }^{238} \mathrm{U} \\
\text { photo fissions induced by gammas. Fission } \\
\text { rate linear with gamma emission rate. } \\
\text { Variable gains to allow many decades of flux } \\
\text { detection. }\end{array}$ \\
\hline $\mathrm{n} / \gamma$ CONVERTOR & $\begin{array}{l}\text { BC403 scintillator plate }+ \text { PMT, } \\
\text { collimated, direct } 90^{\circ} \text { convertor } \\
\text { plate view. }\end{array}$ & $\begin{array}{l}\text { Scintillator light output vs. time } \\
\text { corresponding to neutron emission rate. } \\
\text { Neutrons converted to gammas by Al } \\
\text { convertor plate }\end{array}$ \\
\hline $\begin{array}{l}\text { CVD Diamond } \\
\qquad \mathbf{P}\end{array}$ & $\begin{array}{l}\text { CVD Diamond solid state array, } \\
\text { collimated, shielded view, } \\
\text { multiple gains. }\end{array}$ & $\begin{array}{l}\text { Current rate vs. time corresponding to } \\
\text { assembly neutron and gamma emission } \\
\text { rates. Neutron/gamma signals separated by } \\
\text { voltage. Variable gains to allow many } \\
\text { decades of flux detection. }\end{array}$ \\
\hline $\begin{array}{l}\text { PROTON RECOIL } \\
\mathbf{S}\end{array}$ & $\begin{array}{l}\text { Proton/a-Si recoil PIN diode. } \\
\text { Collimated, shielded view. }\end{array}$ & $\begin{array}{l}\text { Current rate vs. time corresponding to } \\
\text { assembly neutron emission rate at the } \\
\text { detector axial position. }\end{array}$ \\
\hline Si PLATE & $\begin{array}{l}\text { Si plate + PCM, shielded pinhole } \\
\text { view. }\end{array}$ & $\begin{array}{l}\text { PCM charge vs. time per pixel corresponding } \\
\text { to neutron spatial emission rate. }\end{array}$ \\
\hline $\begin{array}{l}\text { SCINTILLATOR } \\
\text { (ALPHA BOX) } \\
\text { P }\end{array}$ & $\begin{array}{l}\text { BC403 scintillator cube viewed } \\
\text { by } 4 \text { detectors (PMTs and/or } \\
\text { PDs) }\end{array}$ & $\begin{array}{l}\text { Scintillator light vs. time corresponding to } \\
\text { neutron and gamma spatial emission rates. }\end{array}$ \\
\hline $\begin{array}{l}\text { NEUTRON TRAP } \\
\mathbf{S}\end{array}$ & $\begin{array}{l}\text { Large BC403 scintillator cube } \\
\text { viewed by PMT, time gated }\end{array}$ & $\begin{array}{l}\text { Scintillator light from proton capture } \\
\text { gammas after long time gate corresponding } \\
\text { to total neutron yield. }\end{array}$ \\
\hline $\begin{array}{c}\text { TOF } \\
\mathbf{P}\end{array}$ & $\begin{array}{l}\text { Thin liquid scintillator, } \\
\text { evacuated flight path, and } \\
\text { larger plastic scintillator } \\
\text { provide timing signals of } \\
\text { individual neutron scattering } \\
\text { and capture in scintillators. }\end{array}$ & $\begin{array}{l}\text { Flight time between detector elements } \\
\text { provides precise neutron energy } \\
\text { determination of individual neutrons. }\end{array}$ \\
\hline $\begin{array}{l}\text { NE213 } \\
\mathbf{S}\end{array}$ & $\begin{array}{l}\text { Liquid scintillation detector } \\
\text { system with pulse shape } \\
\text { discrimination. }\end{array}$ & $\begin{array}{l}\text { Scintillator light pulse height output related } \\
\text { to incident neutron energy. Relatively } \\
\text { complex de-convolution necessary to } \\
\text { determine neutron energy spectrum. Gamma } \\
\text { signals can be suppressed by pulse shape } \\
\text { discrimination. }\end{array}$ \\
\hline
\end{tabular}




\begin{tabular}{|c|c|c|}
\hline $\begin{array}{l}\text { Type and } \\
\text { Designation }\end{array}$ & Description & Measured Quantity \\
\hline $\begin{array}{l}\text { ROSPEC } \\
\mathbf{P}\end{array}$ & $\begin{array}{l}\text { Detector system comprised of } \\
\text { several gas filled chambers. The } \\
\text { gases are ionized by neutrons } \\
\text { and each chamber is sensitive } \\
\text { to different neutron energy } \\
\text { bands. }\end{array}$ & $\begin{array}{l}\text { Current of anodes corresponding to neutron } \\
\text { flux at chamber. Software used to de- } \\
\text { convolute signals from the chambers to } \\
\text { determine the neutron energy spectrum. }\end{array}$ \\
\hline $\begin{array}{l}\text { CR-39 PACK } \\
\mathbf{S}\end{array}$ & $\begin{array}{l}\text { CR-39 film pack, shielded } \\
\text { pinhole view. }\end{array}$ & $\begin{array}{l}\text { Etched holes in film corresponding to } \\
\text { integrated neutron yield. }\end{array}$ \\
\hline $\begin{array}{l}\text { BUBBLE } \\
\text { DETECTOR } \\
\mathbf{P}\end{array}$ & $\begin{array}{l}\text { Bubble detectors containing } \\
\text { superheated liquid. }\end{array}$ & $\begin{array}{l}\text { Number and size of bubbles caused by } \\
\text { neutron interactions in the liquid. The } \\
\text { number and size of bubbles are related to the } \\
\text { number of neutrons, energy deposited, and } \\
\text { neutron dose. }\end{array}$ \\
\hline $\begin{array}{l}\text { MULTISPHERE } \\
\text { BONNER SPHERE } \\
\text { P }\end{array}$ & $\begin{array}{l}\text { Ionization detector surrounded } \\
\text { by different thicknesses of } \\
\text { polyethylene. }\end{array}$ & $\begin{array}{l}\text { Anode current of each configuration. } \\
\text { Software is used to unfold the neutron } \\
\text { energy spectrum from the signals detected } \\
\text { for different thicknesses of polyethylene. }\end{array}$ \\
\hline $\begin{array}{l}\text { ACTIVATION } \\
\text { AND RADCHEM } \\
\text { FOILS } \\
\text { P }\end{array}$ & $\begin{array}{l}\text { Activation foils located exterior } \\
\text { to assembly at various } \\
\text { locations. Various foil materials } \\
\text { and shields. }\end{array}$ & $\begin{array}{l}\text { Neutron induced radioactivity corresponding } \\
\text { to integrated neutron flux at foil location. } \\
\text { Foil shields and sandwiching provide some } \\
\text { spectral information. }\end{array}$ \\
\hline $\begin{array}{l}\text { THERMAL } \\
\text { CAMERA } \\
\mathbf{S}\end{array}$ & $\begin{array}{l}\text { Optical camera to measure } \\
\text { temperature of the assembly } \\
\text { surface }\end{array}$ & $\begin{array}{l}\text { Infrared light emitted from a hot surface } \\
\text { which is related to the temperature of the } \\
\text { surface. }\end{array}$ \\
\hline $\begin{array}{l}\text { PDV/VISAR } \\
\mathbf{S}\end{array}$ & $\begin{array}{l}\text { VISAR/PDV system FO directed } \\
\text { on outside surface of assembly }\end{array}$ & $\begin{array}{l}\text { Changes in interference pattern as a function } \\
\text { of time corresponding to surface outward } \\
\text { velocity as a function of time. }\end{array}$ \\
\hline PINSHORTS & Shorting pin set located at $0.2 \mathrm{~L}$. & $\begin{array}{l}\text { Time progression of pin shorts } \\
\text { corresponding to the arrival time of the } \\
\text { outer metal surface of assembly at the pins. }\end{array}$ \\
\hline $\begin{array}{c}\text { RFS } \\
\mathbf{S}\end{array}$ & $\begin{array}{l}\text { Retroreflective shadowgraphy } \\
\text { system with high-speed camera. }\end{array}$ & $\begin{array}{l}\text { Time variations in image distortions on } \\
\text { reflective screen caused by index changes in } \\
\text { air due to shock propagation. Large } \\
\text { movements of assembly can also be } \\
\text { photographed. }\end{array}$ \\
\hline
\end{tabular}




\section{Description of Primary and Secondary Diagnostics}

\section{Compton Diodes}

Fission gammas can be detected by measuring the electron current generated by Compton scattering in a target. Proper selection of entrance and exit window, and cathode materials can be used to optimize the detection of $1-3 \mathrm{MeV}$ gammas consistent with the energy spectrum of fission gammas. A schematic of such a device is provided below.

Sensitivity: < 1 ns response time with typically $5 \times 10^{-3} \mathrm{e}^{-/} \mathrm{MeV}$ Dynamic Range: Up to 100 A with linear response

$\underline{\text { Advantages }}$

- Useable in high flux conditions (max flux of $10^{23} \mathrm{MeV} / \mathrm{cm}^{2} \mathrm{sec}$ )

- Large dynamic range

- Sensitivity roughly flat over fission gamma energy spectrum.

Disadvantages

- No energy spectrum information

- Very Low sensitivity applicable to only the peak fluxes

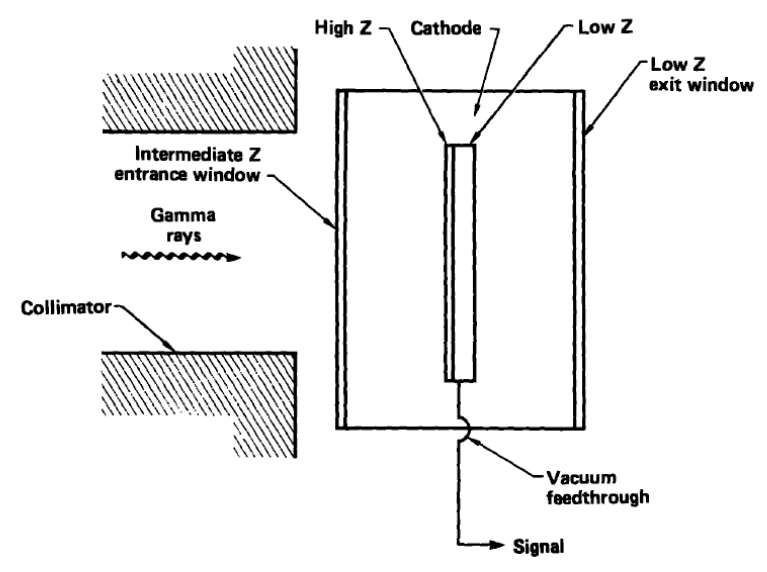

Figure 13. A cylindrical Compton diode whose material and thickness are chosen to optimize sensitivity in the 1- to 3 -MeV energy range. This detector is designed to operate in a collimated gamma-ray beam. 


\section{Proton Recoil}

Neutrons can be measured by detection of recoil protons by a PIN diode. A thin poly sheet is placed in the neutron flux path as the target. Recoil protons are generated by neutron elastic scattering off the hydrogen in the poly. The protons are detected by a PIN diode which is located out of the neutron flux path to reduce background. A Faraday cup can also be used to collect protons if less sensitivity is necessary. The angle between the path of the recoil protons and the incident neutron flux should be kept small to maximize the differential scattering cross section which varies as the cosine of the angle and the proton energy which varies as the square of the cosine.

A schematic of the detector is provided below (Ebert 1986). The recoil proton flight path must be kept at vacuum and a thin Al ranging filter can be placed at the PIN diode to remove scattered electron background as well as lower energy protons. With regard to that function, the detector sensitivity can be tuned to only the higher energy tail of the fission spectrum thereby reducing tome of flight time dispersion. Another variant of the proton recoil type detector is discussed by Ouyang (NIM A, $481,2002)$ where the proton convertor, absorber, detector, and insulating layers are all sandwiched together for direct-on neutron measurement in high flux pulsed reactor applications.

Similarly, an a-Si disk can be used as the neutron target. In this case, neutron captures on Si produce alpha and deuteron charged particles which can be detected by the PIN diode. The appropriate angle for off-axis detection will need to be determined.

Sensitivity: 3 - 5 ns response time

Dynamic Range: 3 - 10 A with linear response

Advantages

- Useable in high flux conditions

- Large dynamic range

- May be located close to assembly to minimize time dispersion.

Disadvantages

- Low sensitivity due to ranging filter and angled flight path. May be susceptible to high relative background. 

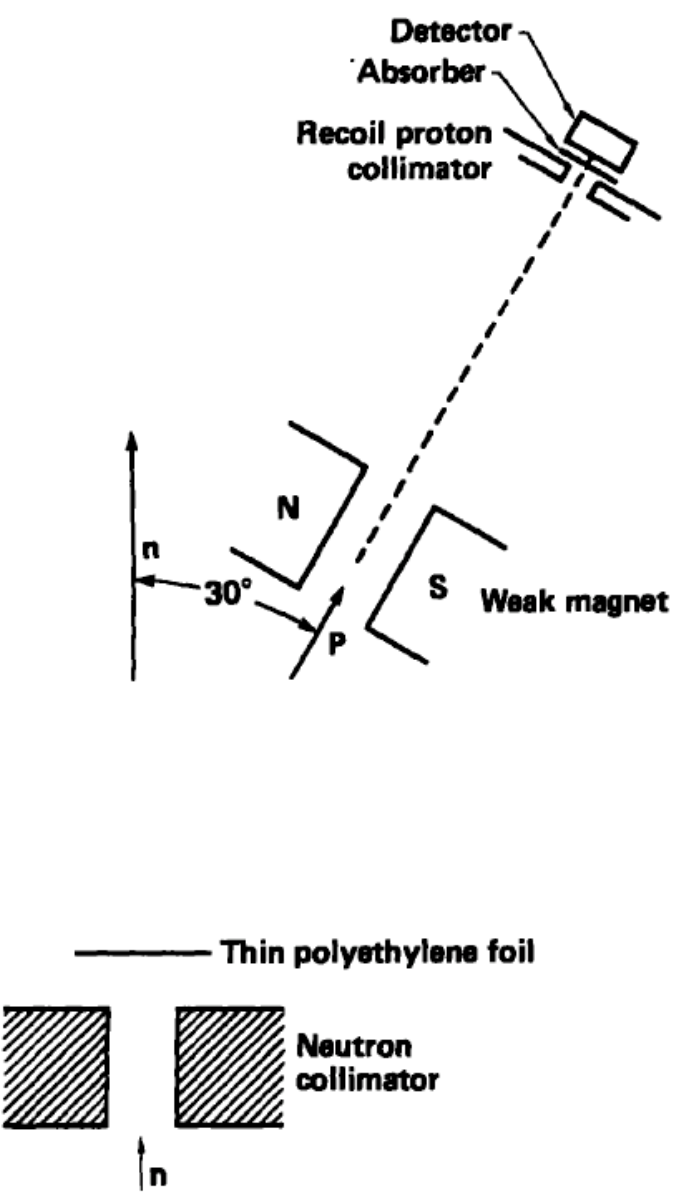

Figure 7. Schematic diagram of a recoil proton detector. The collimated neutrons collide elastically with protons in the polyethylene. Protons scattered at $30^{\circ}$ are detected with a silicon (Si) detector that is shielded from light and lowenergy charged particles by a very thin absorber and a weak magnetic field, respectively. 


\section{Micro-FMs}

Fission chambers have long been used for measurement of neutron flux in nuclear reactors and more recently in fusion reactors. Recent developments in miniature "micro-fission" chambers by KSU (McGregor 2005) are of particular interest. Given their small size ( $\sim 2 \mathrm{~cm}$ across by $\sim$ few $\mathrm{mm}$ deep) it is possible to directly insert several into the fissile core of the experiment without significant perturbation to the fission density and flux. They are insensitive to gammas and able to operate in high flux environments. However, current prototypes have dead times of about $25 \%$ for neutron fluxes of $5 \times 10^{12} \mathrm{n} / \mathrm{cm}^{2} \mathrm{sec}$ when operating in pulse mode. Extension to higher fluxes could perhaps be done by operating in current mode, using a lower density of active fissile material, and a higher threshold energy fission isotope.

A diagram of the KSU micro-fission chamber is provides below as well as a measured output of one such device in the KSU reactor pool.

A similar commercially available micro-FM is also now available from Photonis. This detector was originally developed by CEA. The very small cylindrical active region is only $1.5 \mathrm{~mm}$ in diameter and operable to fluxes up to $5 \times 10^{14} \mathrm{n} / \mathrm{cm}^{2} \mathrm{sec}$.

Sensitivity: $\quad$ Dependent on gas pressure and fissile density on active coated surfaces

Dynamic Range: in excess of $5 \times 10^{12} \mathrm{n} / \mathrm{cm}^{2} \mathrm{sec}$

Advantages

- Usable in high flux conditions (current mode in fluxes exceeding of $10^{12}$ $\mathrm{n} / \mathrm{cm}^{2}$ )

- No noticeable performance degradation for fluences exceeding $10^{19} \mathrm{n} / \mathrm{cm}^{2}$

- Insensitive to gammas

- Provides temporal and spatial data.

Disadvantages

- Use in fluxes in excess of $5 \times 10^{12} \mathrm{n} / \mathrm{cm}^{2} \mathrm{sec}$ has not been demonstrated. 


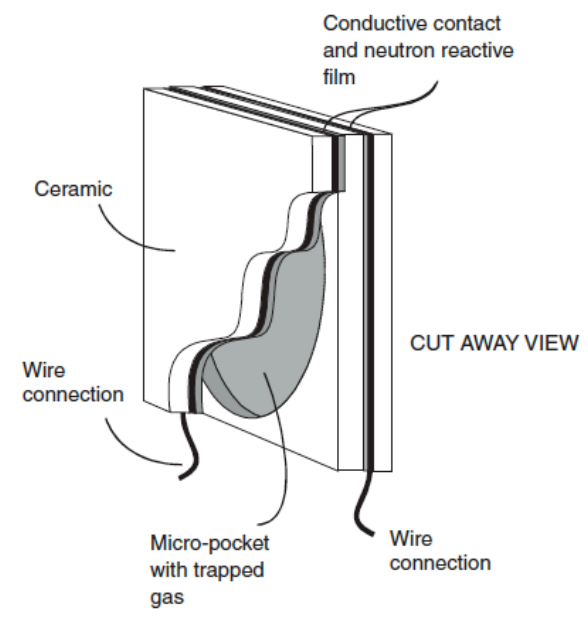

Fig. 1. The micro-pocket fission detector (MPFD) is formed from insulating materials, such as aluminum oxide or oxidized silicon wafers. The opposing sides of each pocket are coated with a conductor followed by a neutron reactive film, such as ${ }^{10} \mathrm{~B},{ }^{6} \mathrm{LiF},{ }^{235} \mathrm{U}$, or ${ }^{232} \mathrm{Th}$
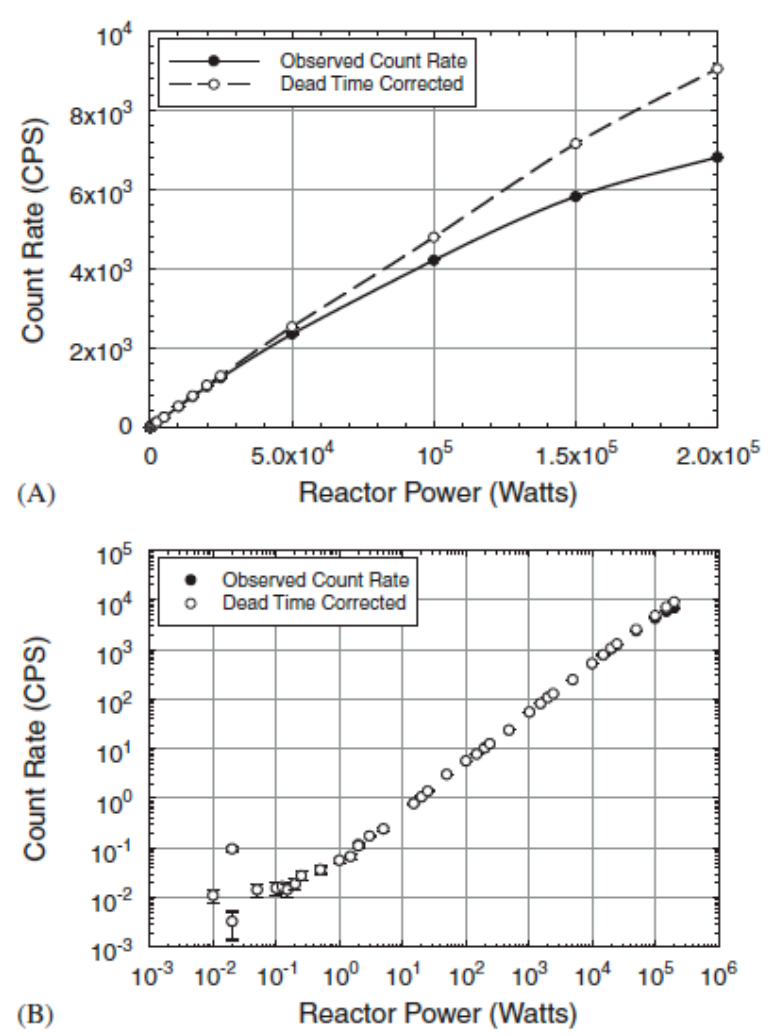

Fig. 7. The above figures show the response of a 3-mm diameter, 1-mm wide MPFD as a function of reactor power as inserted into the center of a $250 \mathrm{~kW}$ TRIGA Mark II nuclear reactor, where (A) is a linear plot and (B) is a $\log -\log$ plot. The most recent devices are only $1 \mathrm{~mm}$ in diameter, and are expected to perform with no appreciable deadtime losses with the TRIGA reactor at full power $\left(\phi_{\text {th }}>10^{13}\right.$ neutrons $\left.\mathrm{cm}^{-2} \mathrm{~s}^{-1}\right)$. 


\section{CVD Diamond}

Schmidt (Rev. Sci. Intrum., 74, 2003) reports testing of several CVD diamond detectors at OMEGA. The response for "optical grade" CVD diamond to $2.45 \mathrm{MeV}$ neutrons from DD fusion is provided below. CVD diamond detectors will be used at NIF for the highest expected neutron yields of $10^{15}-10^{19}$. It has been reported (Almaviva 2009) that high neutron fluxes in excess of $10^{16} \mathrm{n} / \mathrm{cm}^{2} \mathrm{sec}$ causes degradation of CVD diamond detectors. Shielding could be used to reduce the neutron flux at the detectors if necessary to remain well within established operating conditions.

Temporal: 400 ps FWHM. Peak locatable to better than 100 ps

Sensitivity: $0.26 \mu \mathrm{Vns} / \mathrm{n}$

Advantages

- Usable in high flux conditions

- Fast temporal response

- Large dynamic range

- Insensitive to gammas and radiation hard

\section{Disadvantages}

- Low detection efficiency

(Though diamond has highest detection efficiency theoretically, efficiency is greatly limited by the thickness of the diamond wafer $(1 \mathrm{~mm})$ which can be manufactured).

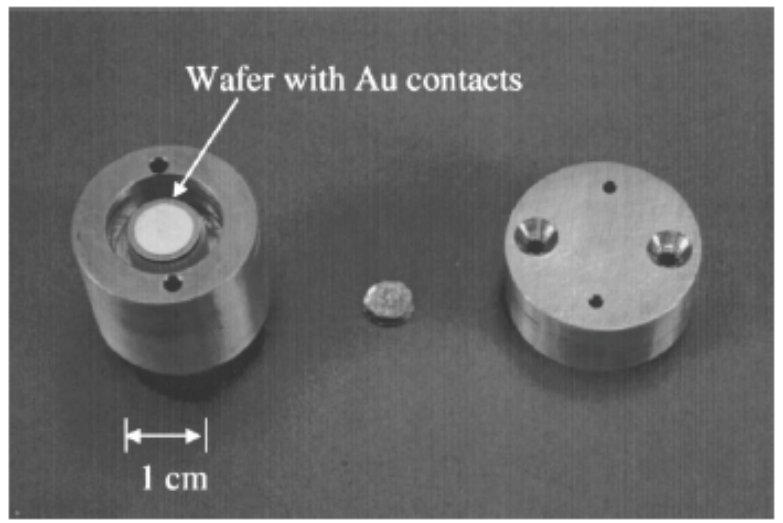

FIG. 2. Disassembled CVD diamond detector. The CVD diamond wafer sits in the $\mathrm{Cu}$ housing on left. The Au contact on the bottom of the wafer connects to the central pin of the SMA connector. To seal the assembly, $\mathrm{Cu}$ top (right) bolts to body of housing (left). This grounds the top Au contact. 
1830 Rev. Sci. Instrum., Vol. 74, No. 3, March 2003
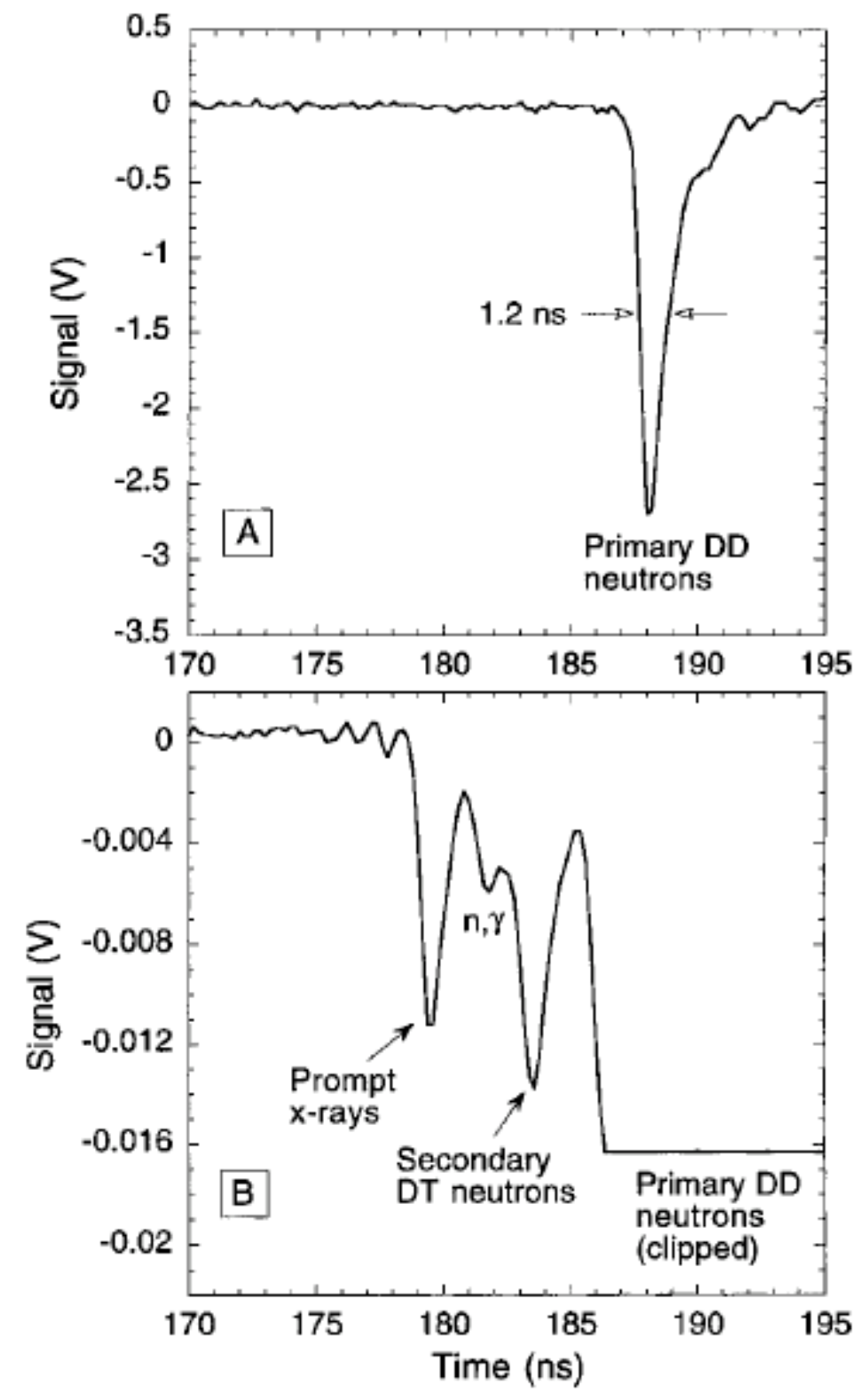

FIG. 4. Response of CVD diamond detector to OMEGA shot 27449 (D2 fuel). The signal was split into two scope channels, A and B. Channel B, with the expanded vertical axis, sends the primary signal off-scale. The total neutron yield for this shot was $1.62 \times 10^{11}$. The detector was at $16 \mathrm{~cm}$ from magnet chamber center. 


\section{Scintillator - Alpha Box}

An alpha box has been developed, tested, and maintained by the Test Rediness Program. This detector will be fielded by Test Readiness for both Godiva IV and Juliet operations. The detector is essentially a modern version of UGT diagnostics where modern fast electronics has been located with the scintillator and photodetectors in a single housing. The housing is heavily shielded and provides mitigation of emf. Neutron and gamma radiation cause scintillations which are detected by 4 detectors of different gains, typically 3 PMTs and 1 PD. For higher flux levels, one or more PMTs can be replaced by PDs. Given the different sensitivities, a very large dynamic range is possible. Detector coverage and output from two alpha boxes at a recent test at the Z-machine at Sandia are provided below (1" Pb shielding used for actual shot data).

\section{Advantages}

- Already available

- Large dynamic range (over 7 orders of magnitude)

- Shielded for emf

Disadvantages

- Sensitive to both neutrons and gammas

- Shielding or large stand off distance may be needed

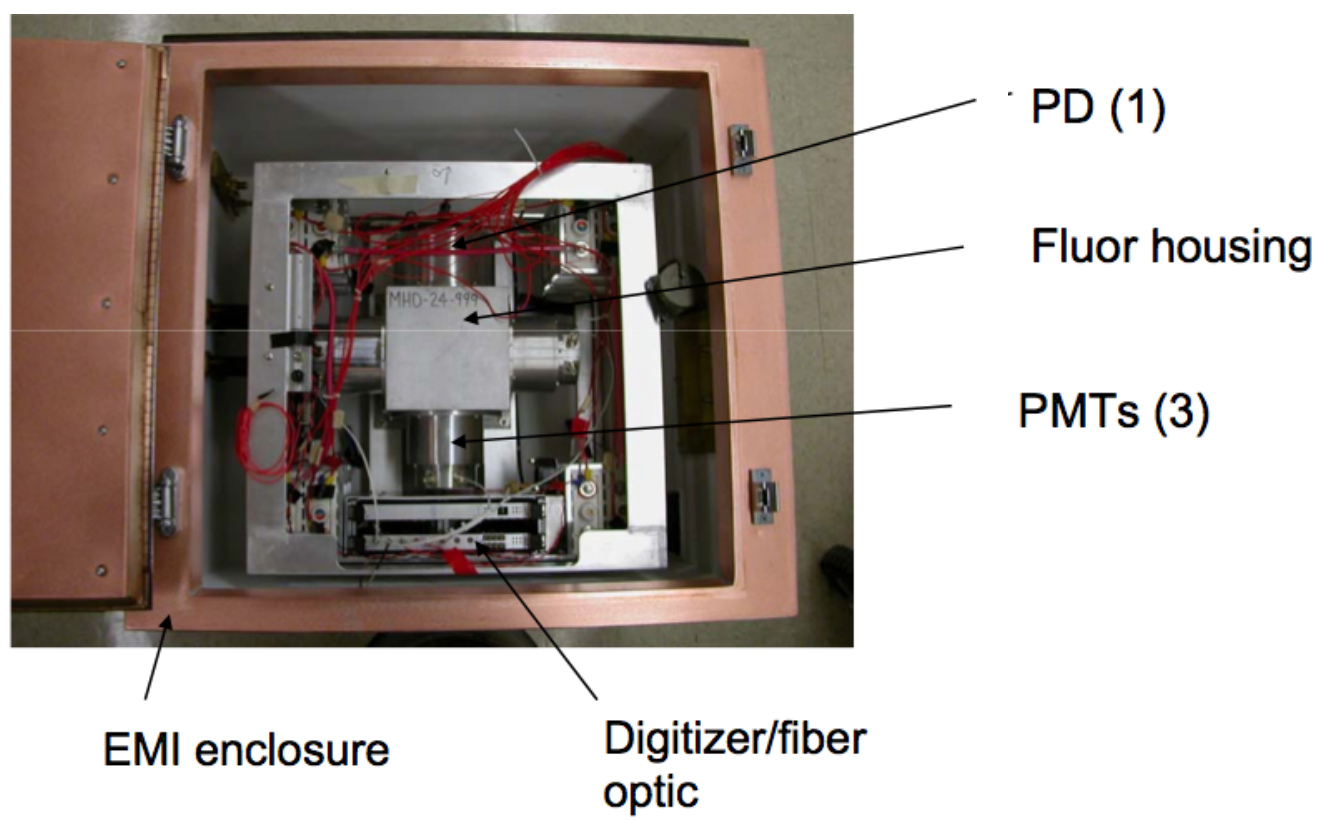

transmitter 

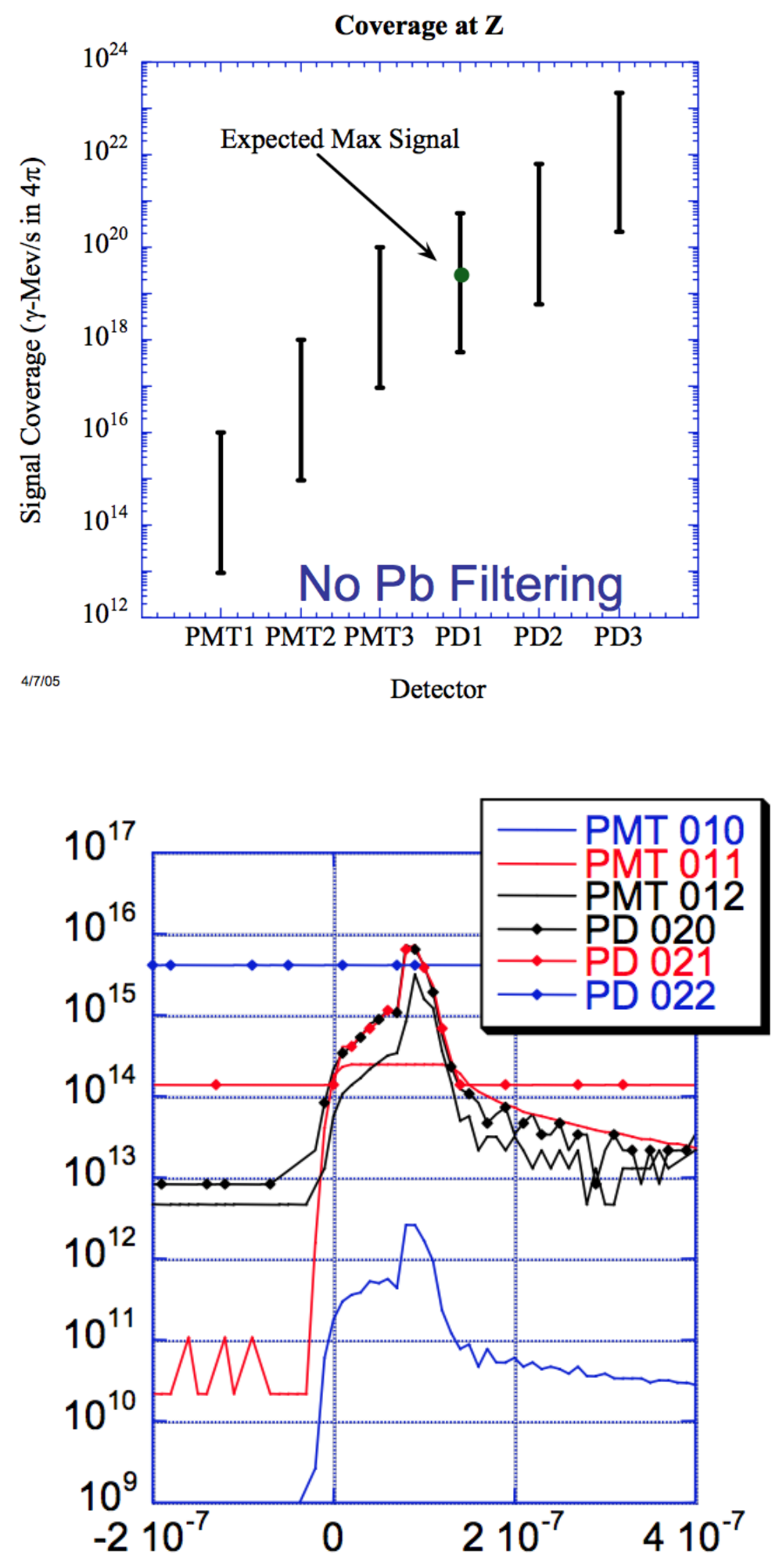


\section{NE213 Liquid Scintillator}

NE-213 is a liquid scintillation detector that can be used for neutron spectroscopy (Verbinski, V., NIM, 65, 8-25, 1968). It is primarily xylene but has small amounts of other chemicals for wavelength shifting and light-emission. NE-213 has three primary light decay times which are present in different ratios depending upon whether the detected particle was a neutron or a gamma and this difference of ratios of light decay times is what enables the NE-213 to distinguish between neutrons and gammas. The lower energy range for NE-213 is around $500 \mathrm{keV}$ to 700 $\mathrm{keV}$, depending upon the method used for pulse-shape discrimination, while the upper limit is around $20 \mathrm{MeV}$.

\section{ROSPEC Detector (Rotating Spectrometer)}

The ROSPEC detection system uses various gas counters filled with different pressures of hydrogenous gases to measure the neutron energy spectrum of a neutron field using (n,p) reactions (Ing. et. al., Rad Protection Dosimetry, 70, No. 1-4, 273-278)(Heimbach, C., J. of Res. of NIST, 111, 419-428, 2006). The detectors measure hydrogen recoil from elastic neutron scattering and the spectra is unfolded. To avoid spatial differences in the measured neutron fluences, the gas counters are mounted on a slowly rotating bed so that they will all cover the same area. Energy spectra can be from $50 \mathrm{keV}$ to $16 \mathrm{MeV}$ (with use of an optional plastic scintillator for the high energy end).

\section{Bubble Detectors}

Bubble detectors (or bubble chambers) use a near-boiling or superheated liquid in a container to detect particles (in this case, neutrons). As the neutrons interact with the liquid, the energy transfer to the superheated liquid causes the liquid to vaporize, which forms a bubble in the liquid. The number and size of the bubbles will be related to the amount of energy deposited in the liquid, which can be related to the number of neutron interactions or the neutron dose (Glaser, D., Phys. Rev., 87, $4,665-665,1952)$.

\section{Multisphere/Bonner Spheres}

Bonner spheres use thermal neutron detectors that are placed in various thicknesses (spheres) of neutron moderators (poly, etc.). The different thicknesses of moderator around each detector will change the neutron energy that the detector will experience, which leads to varying detector responses from each detector based upon the incident neutron energy and the amount of moderator around each detector. Examining the detector responses from each Bonner sphere can allow for a determination of the neutron spectra (Esposito, A., Rad Protection Dosimetry, 110, No. 1-4, 555-578, 2004)(Thorngate, J., LLNL Report, UCID-21574, 1988). 


\section{Activation and RadChem Foils}

Activation foils have been used extensively to characterize radiation fields at pulsed reactors and other high radiation environments (Holt, P., Rad Protection Dosimetry, 10, no 1-4, 251-264, 1985). Integrated neutron fluence at several location within and external to the assembly can be measured with the foils. Different foil materials and shields can be used to grossly measure the neutron energy spectrum. Recently, Kelly (IEEE Trans. Nuc. Sci., V40, 6, 1993) used foils to benchmark Sandia's SPR-III pulsed reactor neutron spectrum inside the cavity. A large number of activation materials over a number of separate pulses were used (see Table below). The activation of the foils, in conjunction with Monte Carlo modeling and in-house software, was used to deduce the neutron spectrum. Morgan White is also planning on fielding an extensive set of foils using threshold reactions to determine the energy spectrum of an HEU assembly under IER-153. These foils and methodology developed to determine the energy spectrum can be applied to Godiva IV and Juliet as well. The best and minimum set of foils for application to Godiva IV Juliet has not been determined as of yet.

\section{Advantages}

- Usable in high flux conditions

- Insensitive to gammas

- Well established technique

\section{Disadvantages}

- Software needed for spectrum determination

- Time lag between foil retrieval and measurement could reduce accuracy

- Impurities in materials needs to be known and/or pure materials procured. 


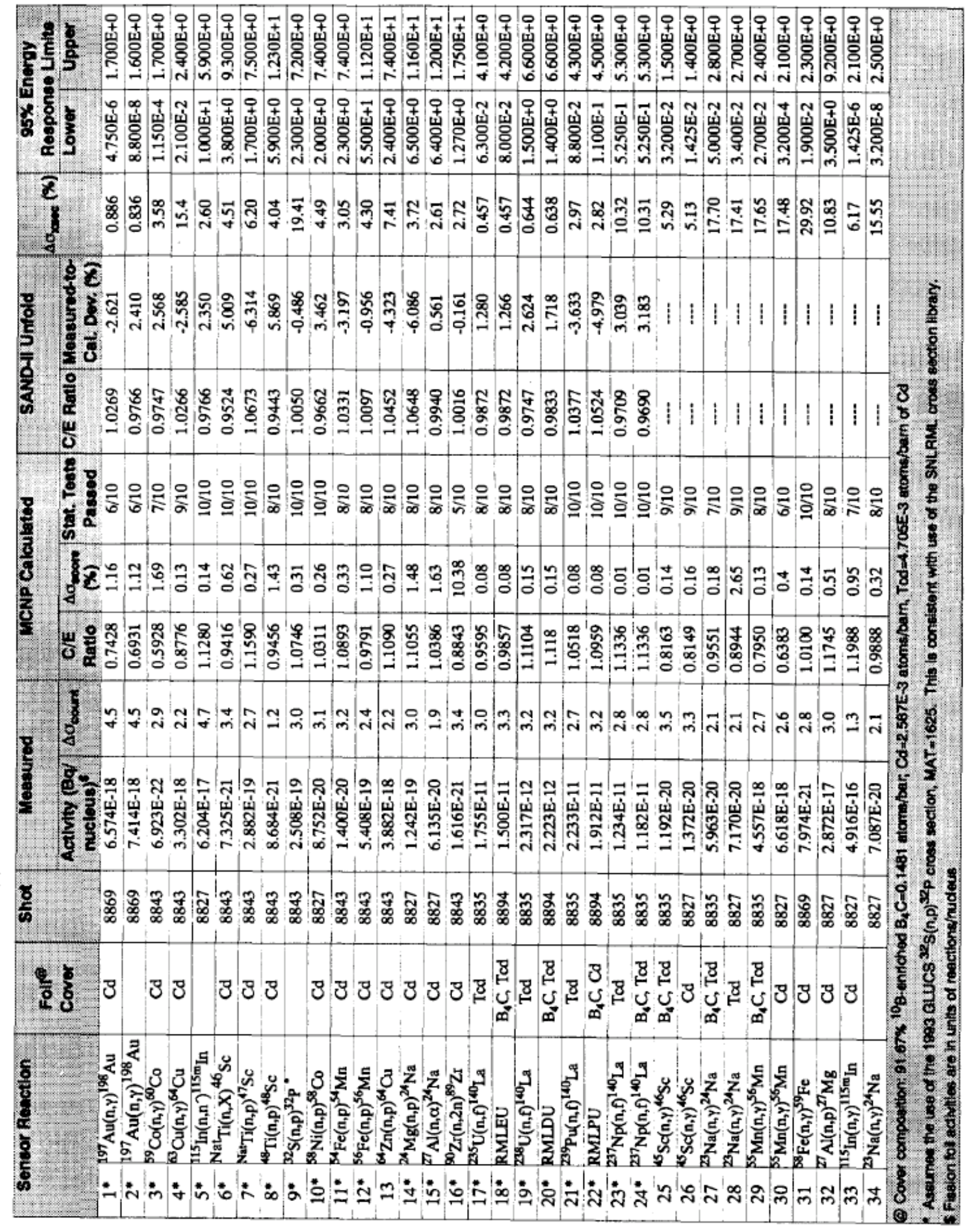




\section{CR-39 Film Pack}

CR-39 film can be used to detect the integrated neutron flux. The film medium itself provides $\mathrm{H}$ targets for neutron scattering and a separate "proton radiator", such as a thin poly sheet, typically used in other methods based on proton recoil, is not needed. The damage to the film medium caused by the recoils can be chemically etched to produce optically measurable holes in the film, the density of which is proportional to the integrated neutron flux.

Frenje (Rev. Sci. Intrum., 73, 2002) describes the use of a stack of 4 CR-39 films, with aluminum ranging filters $(100 \mu \mathrm{m})$ between and outside, to measure $2.45 \mathrm{MeV}$ neutrons from DD fusion. The Al ranging filters prevent protons from reaching adjacent films. The CR-39 stack was located $15 \mathrm{~cm}$ from the DD source with a total neutron yield of $1.3 \times 10^{11}$. The dynamic range may be extendable, as discussed by Frenje, to $10^{12}-10^{13} \mathrm{n}$ with non-linear corrections for track overlap. The measured detector characteristics are provided below.

CR-39 film is used at LLNL in dosimetry applications as well as for calibration of detectors at NIF. The etching and optical reader hardware as well as the necessary experience and proficiency in CR-39 film reading already exist at LLNL.

Sensitivity: $1.1 \times 10^{-4}$ etched tracks/n

Dynamic Range: $3.5 \times 10^{6}-3.5 \times 10^{10} \mathrm{n} / \mathrm{cm}^{2}$ with linear response

Advantages

- Preferred in high flux conditions to other film/track detectors

- Large dynamic range (may be extendable to $10^{12}-10^{13} \mathrm{n}$ )

- Insensitive to gammas

- Well established technique and available at LLNL

Disadvantages

- Improper chemical etching could result in systematic errors. 
(a) DD

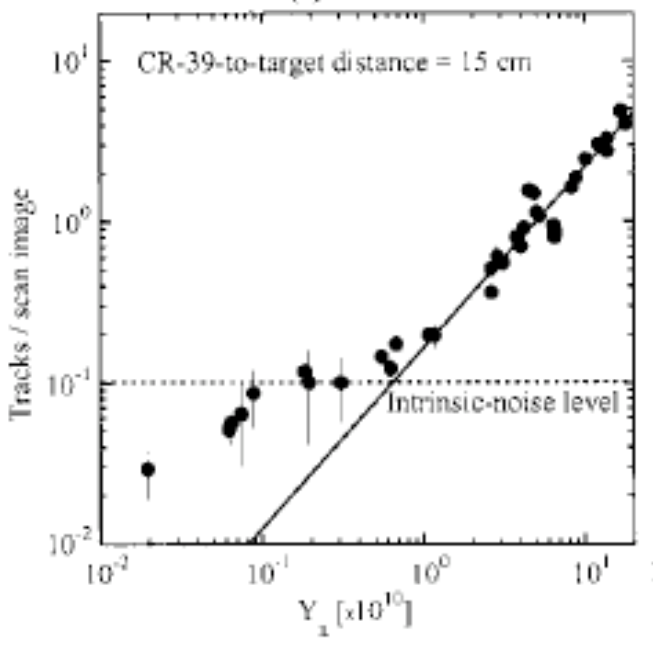

(b) DT

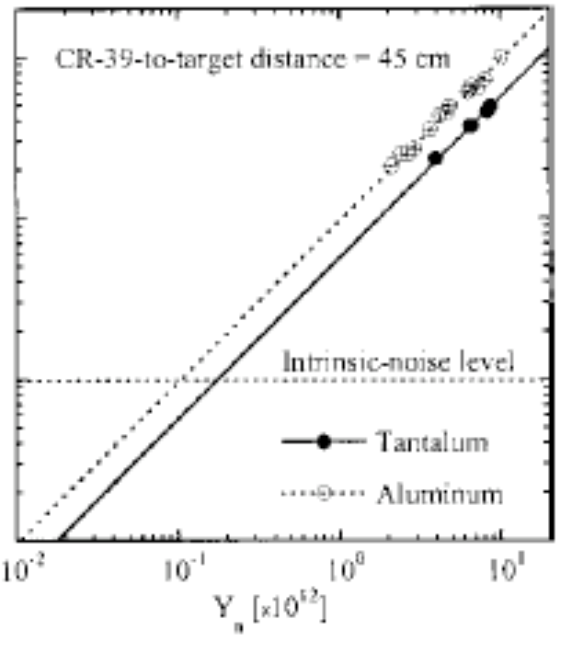

FIG. 12. (a) Number of DD-neutron-induced tracks (within the diameter range $6-12 \mu \mathrm{m})$ per scan image $\left(1.3 \times 10^{-3} \mathrm{~cm}^{2}\right)$ as a function of implosion yield (where the yield was measured with either indium activation or a neutron time-of-flight diagnostic). The data were extracted from the front sides of the CR-39 using scan parameters (85/65/15). The CR-39 detectors were located $15 \mathrm{~cm}$ from the target in all cases. The solid line indicates a linear fit to the data above a neutron yield of $10^{10}$, indicating that useful yield estimates can be made in that regime. Intrinsic noise, nominally indicated by the horizontal dotted line, dominates at lower yields. (b) Number of DT-neutron-induced tracks (within the diameter range 6-12 $\mu \mathrm{m}$ ) per scan image is plotted as a function of DT neutron yield determined from copper activation. The data were acquired using aluminum or tantalum filters in front of the CR-39. The CR-39 pieces were located $45-60 \mathrm{~cm}$ from the targets, but all data are normalized to $45 \mathrm{~cm}$ by correcting for $R^{-2}$ and for backscatter effects. It can be seen that the aluminum filter acts as an external charged-particle source and increases the number of neutron-induced tracks by about $60 \%$ in the CR-39 (relative to tantalum). The DT data show a strong linear correlation between track density and neutron yield, and extrapolation to lower neutron yield indicates that at $15 \mathrm{~cm}$ from the target the method should work down to at least $10^{10}$, where intrinsic noise would start to dominate. There is an upper limit on yield for this method of about $10^{14}$, where track overlap in the CR-39 starts to be significant. 


\section{Time of Flight}

The Advanced Detector Design Group at LLNL has provided a preliminary design for a TOF spectrometer. The TOF detector in conjunction with a ${ }^{3} \mathrm{He}$ ionization tube can provide spectral coverage for neutron energies from a few $\mathrm{keV}$ to over $10 \mathrm{MeV}$. The spectrometer consists of two scintillators with a $1 \mathrm{~m}$ long drift tube between them. The time difference measured between interactions of individual neutrons in the front and back scintillators provides a very accurate energy measurement to within a few \%. A liquid scintillator in the front can allow for gamma discrimination via pulse shape analysis. Accuracy begins to diminish to $20 \%$ below several hundred $\mathrm{keV}$ where a ${ }^{3} \mathrm{He}$ ionization tube is then used to improve accuracy.

\section{Advantages}

- Most accurate neutron energy measurement method

- Relatively simple hardware and electronics required

\section{Disadvantages}

- Usable only in low flux conditions (necessary for single neutron counting)

- Measures neutrons only in a specific direction

- Relatively large and heavy

\section{Neutron Trap}

LLNL B-division has fielded a simple detector consisting of a large $1 \mathrm{ft}^{3}$ of plastic scintillator coupled to a PMT. Long after the pulse from the reactor is over, some neutrons continue to scatter at thermal temperatures for long time periods of up to msecs. By gating the signal from the PMT, only capture gammas from neutron capture by protons provide a signal at long times. The detected number of gammas is related to the total neutron yield of the pulse. This detector was successfully fielded on Full Toss but would need to be fully calibrated for Godiva IV and Juliet use with respect to room return signatures at delayed fission gammas and neutrons which also occur at late times.

\section{VISAR/PDV}

VISAR (Velocity Interferometry System for Any Reflectors) and PDV (Photonic Doppler Velocimeter) are interferometry techniques which allow the measurement of complete time histories of the motion of a surface for very fast reaction times, such as shocks. Crump (SAND92-0162) describes a modification to the basic technique, known as Fixed Cavity VISAR, which allows the triggering of recording 
equipment on the initial motion of the measured object. This would be appropriate given the imprecise knowledge of the reaction and shock generation in the Godiva IV or Juliet assemblies.

The primary components of a typical VISAR set-up are a single frequency laser, modified unequal leg Michelson interferometer cavity, high-speed PMTs, and a digitizing oscilloscope. A sketch of a Fixed Cavity VISAR is provided below with description of operation provided in the reference. A typical data output from a multipoint VISAR is also shown below.

Both VISAR and PDV have been used extensively for subcritical and hydro tests.

\section{Advantages}

- Usable in high EMF conditions

- Not sensitive to ionizing radiation

- Well known/used technique at LLNL

- Portable PDV module already developed and available

Disadvantages

- $\quad$ VISAR and PDV if built from scratch are expensive.

\section{Retroreflective Shadowgraphy}

Retroreflective shadowgraphy is an old visual technique developed by Edgerton. A simple set-up includes a light source (arc lamp), fast camera ( $>250,000 \mathrm{fps}$ ), and retroreflective screen (commercially available). This technique has been used to visualize explosive shocks in air as well as many other dynamic events causing refractive index changes in air (Hargather 2009). Diagrams and pictures of a typical shadowgraphy setup and results are shown below. 

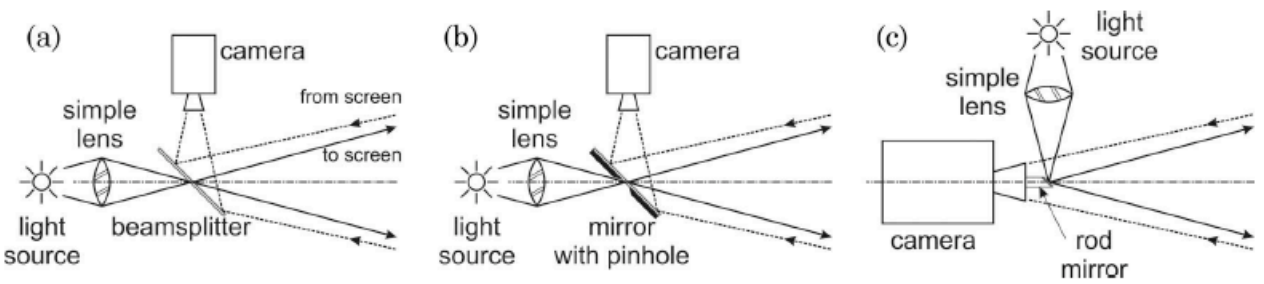

Fig. 3. Diagrams of the coincident illumination setups for retroreflective shadowgraphy, using (a) a beam splitter, (b) a mirror with a "pinhole," and (c) a rod mirror.

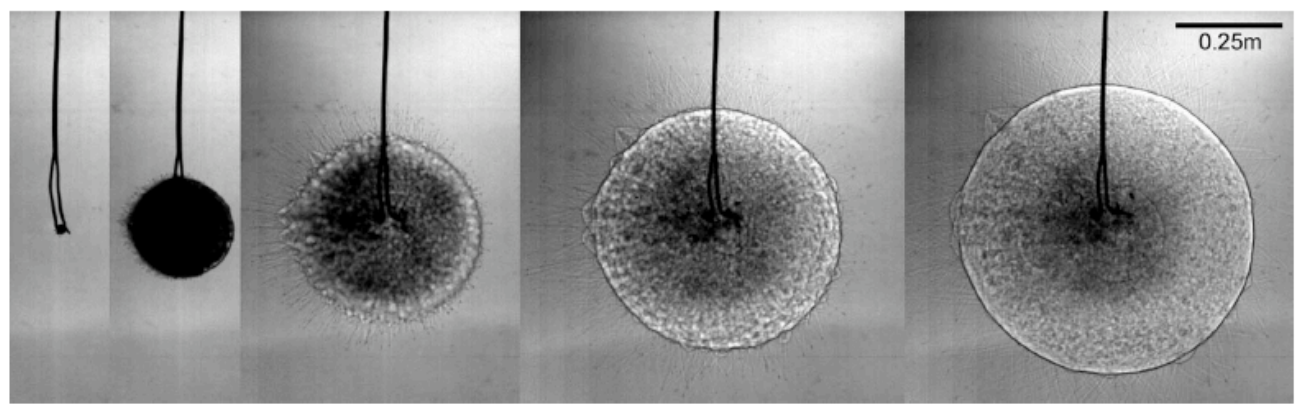

Fig. 5. Digital image series showing shadowgrams of a $1 \mathrm{~g}$ TATP explosion.

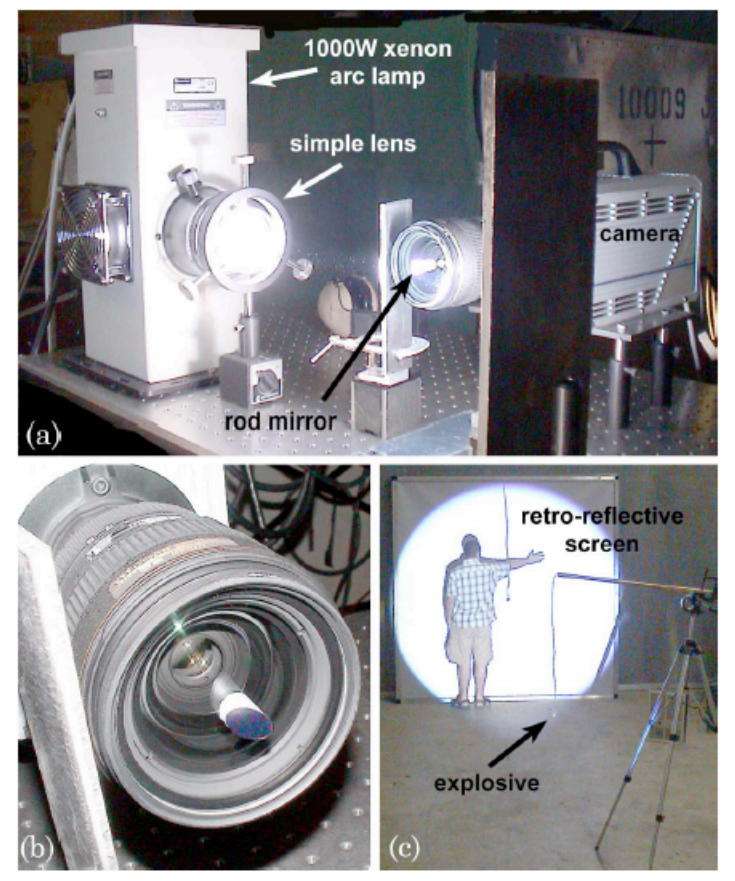

Fig. 4. (Color online) (a) Oblique side view of the camera/illuminator assembly, with vertical plates used as beam stops. (b) APXRS digital camera with a $20-70 \mathrm{~mm}$ Nikon zoom lens and the rod mirror mounted on a clear lens filter. (c) An explosive charge is suspended by a wire in the foreground while the author (MJH) stands before the retroreflective screen in the background, on which the shadowgram of the suspended charge can be observed. 